
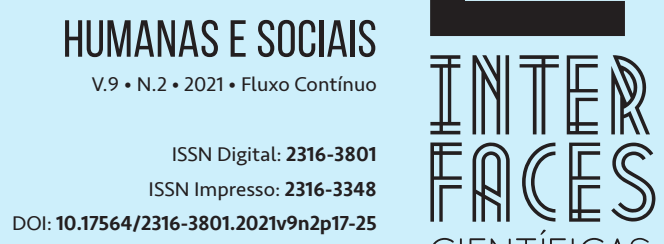

CIENTÍFICAS

\section{TERRITORIALIDADES, MULHERES E CÁRCERE}

TERRITORIALITIES, WOMEN AND PRISON

TERRITORIALIDADES, MUJERES Y PRISIONES
Alba Maria Bomfim de França ${ }^{1}$ Jesana Batista Pereira ${ }^{2}$ Vivianny Kelly Galvão ${ }^{3}$

\section{RESUMO}

O presente estudo teórico teve como objetivo refletir acerca de territorialidades e mulheres no cárcere. Trata-se de uma análise reflexiva originária de questionamentos em torno das territorialidades, a qual suscitou reflexões sobre como estas são representadas e relacionadas por mulheres no presídio. Este estudo estruturou-se em duas seções principais. Na primeira seção são apresentados conceitos e utilizações de território e territorialidade, assim como, de sua perspectiva sociopolítica e cultural. Em seguida, na segunda seção, reflete-se sobre territorialidades e mulheres no cárcere. A partir dos conceitos encontrados neste ensaio, percebeu-se que as dimensões de território e territorialidade perpassam espacialidades e a individualidade dos sujeitos, bem como suas coletividades, cultura, relações sociais e políticas, transpondo esse espaço para uma ordem multi, que se constrói e reconstrói constantemente. Quando tais conceitos são explorados e analisados na perspectiva da mulher na prisão é possível ainda refletir sobre a multiterritorialidade dessas mulheres e as relações de poder que permeiam nesses territórios.

\section{PALAVRAS-CHAVE}

Território Sociocultural. Mulheres. Prisões. 


\section{ABSTRACT}

The present theoretical study aimed to reflect on territorialities and women in prison. It is a reflexive analysis originating from questions about territorialities, which raised reflections on how they are represented and related by women in prison. This study was structured in two main sections. In the first section, concepts and uses of territory and territoriality are presented, as well as from their sociopolitical and cultural perspective. Then, in the second section, it reflects on territorialities and women in prison. From the concepts found in this essay it was noticed that the dimensions of territory and territoriality permeate spatialities and the individuality of the subjects, as well as their collectivities, culture, social and political relations, transposing this space to a multi order, which is constantly constructed and reconstructed. When such concepts are explored and analyzed from the perspective of the women in prison can also reflect on the multiterritoriality of these women and the power relations that permeate these territories.

\section{KEYWORDS}

Sociocultural Territory. Women. Prisons.

\section{RESUMEN}

El presente estudio teórico tiene como objetivo reflexionar sobre territorialidades y mujeres en prisión. Se trata de un análisis reflexivo que nace de cuestiones sobre territorialidades, que suscitó reflexiones sobre cómo están representadas y relacionadas por las mujeres en prisión. Este estudio se estructuró en dos secciones principales. En la primera sección se presentan conceptos y usos del territorio y la territorialidad, así como desde su perspectiva sociopolítica y cultural. Luego, en la segunda sección, reflexiona sobre territorialidades y mujeres en prisión. De los conceptos encontrados en este ensayo se notó que las dimensiones del territorio y la territorialidad impregnan las espacialidades y la individualidad de los sujetos, así como sus colectividades, cultura, relaciones sociales y políticas, transponiendo este espacio a un orden múltiple, que se construye y reconstruye constantemente. Cuando tales conceptos son explorados y analizados desde la perspectiva de las mujeres en la cárcel también es posible reflexionar sobre la multiterritorialidad de estas mujeres y las relaciones de poder que impregnan estos territorios.

\section{PALABRAS CLAVE}

Territorio sociocultural. Mujeres. Prisiones. 


\section{INTRODUÇ̧̃̃o}

Em termos gerais, o território está relacionado a áreas demarcadas e espacialidades, geográficas ou não. Todavia, alguns estudiosos apontam que, desde sua origem, o termo remete a uma dupla conotação, a material e a simbólica, perpassando por dimensões políticas, sociais, culturais e econômicas. "Trata-se, isto sim, de um espaço-processo, um espaço socialmente construído” (HAESBAERT, 2007, p. 21).

O território como espaço de relações, no qual se manifesta a vida cotidiana dos indivíduos e das populações, é resultante de uma acumulação de situações históricas, econômicas, ambientais, sociais e culturais que envolvem os indivíduos (BRASIL, 2014), sendo considerado, nessa perspectiva por alguns autores, como territorialidade, que está "intimamente ligada ao modo como as pessoas utilizam a terra, como elas próprias se organizam no espaço e como elas dão significado ao lugar” (HAESBAERT, 2007, p. 22).

Ainda, faz-se necessária a compreensão de que territórios e territorialidade não são espaços inertes, sedentários. Deste modo, podem possuir em si vários outros territórios - múltiplos territórios, bem como podem ser espaços de múltiplas relações - multiterritorialidade (HAESBAERT, 2007). Estes, fundamentam-se em diversas dimensões de poder, numa perspectiva relacional e diretamente ligada a fatores sociais, políticos, econômicos e culturais. Sob este aspecto, deve-se admitir a existência de territorialidades ligadas as diferenças sexuais e de gênero (SCHEFLER, 2018).

A territorialidade feminina é um fenômeno em constante mutação, entendida como um campo de atuação de relações e disputas de poder em suas práticas cotidianas, relações afetivas, trabalho, políticas, entre outras, que nem sempre são equitativas e, geralmente, são desiguais e vulneráveis (SCHEFLER, 2018).

No que se refere às modalidades das territorializações femininas (enquanto espaços de "exclusão inclusiva" e/ou "territórios de exceção") mais "desterritorializante", "desidentificadora” e "destituidora” de cidadania (HAESBAERT, 2007) podem ser enquadradas as instituições penitenciárias, as quais reafirmam e naturalizam as relações de gênero em territórios desfavoráveis.

Nesta perspectiva, Dalmaso (2017) considera que tais instituições não constituem territórios únicos. Do interior do cárcere emergem e acoplam-se múltiplos territórios que envolvem diferentes demarcações (por exemplo, celas, módulos, espaços coletivos), diferentes grupos (equipes de segurança, mulheres privadas de liberdade) e diferentes sujeitos (prisioneiras, agentes penitenciários, profissionais de saúde, entre outros).

Diante do aqui exposto, este estudo tem como objetivo refletir acerca de territorialidades e mulheres no cárcere.

\section{MÉTODO}

Trata-se de uma análise reflexiva originária de questionamentos em torno da territorialidade. Suscitou-se aqui reflexões sobre territorialidades e como estas são representadas, relacionadas e 
vivenciadas por mulheres no cárcere. Constituiu-se, dessa forma, como fonte de dados deste ensaio teórico, produções apreciadas a partir da busca na literatura em bases de dados científicos, com o uso dos descritores em ciências da saúde - DeCS “Território Sociocultural”, “Mulheres" e "Prisões”, bem como, provenientes de livros e artigos sobre a temática.

Adotou-se no presente estudo, para atender ao objetivo proposto, o entendimento de territorialidade enquanto relação sociopolítico e cultural. Estruturou-se este estudo em duas seções principais. Na primeira seção são apresentados conceitos e utilizações de território e territorialidade, assim como, de sua perspectiva sociopolítico e cultural. Em seguida, na segunda seção, reflete-se sobre territorialidades e mulheres no cárcere ${ }^{4}$.

\section{RESULTADOS E DISCUSSÃO}

\subsection{TERRITÓRIO E TERRITORIALIDADE}

Segundo Deleuze e Guattari (1997, p. 105) “o território é de fato um ato, que afeta os meios e os ritmos, que os 'territorializa”. Nessa perspectiva, os autores chamam a atenção para o fato que o território é construído e que territorializar perpassa além dessa dimensão, como uma ação/relação do sujeito no espaço, geográfico ou não, o qual atua a partir de um processo de domínio (político-econômico) e/ou apropriação (simbólico-cultural).

O fato é que discutir território, implica também uma discussão sobre controle social e político, de conflito e de poder, os quais podem ser construídos e desconstruídos nas mais diversas escalas, tendo caráter permanente, periódica, cíclica ou experiencial (SCHEFLER, 2018).

Para Haesbaert e Bruce (2002), a partir de uma análise da proposta de Deleuze e Guattari, territorialização e desterritorialização são processos concomitantes, fundamentais para compreender as práticas humanas. Surgem nesta perspectiva problemas concretos: "como se dá a construção e a destruição ou abandono dos territórios humanos, quais são os seus componentes, seus agenciamentos, suas intensidades?" Consideram então a existência de uma "des-re-territorialização".

Para os autores, esta trata-se de um movimento de construção do território, o que significa que "a vida é um constante movimento de desterritorialização e reterritorialização, ou seja, estamos sempre passando de um território para outro, abandonando territórios, fundando novos" (HAESBAERT; BRUCE, 2002, p. 19).

Haesbaert (2007) afirma que não basta pensar no movimento des-re-territorialização, sem pensar na multiterritorialidade, a qual considera enquanto processo de territorialização que parte do nível individual ou de pequenos grupos. Assim, toda relação social, individual ou coletiva, implica uma interação territorial, um entrecruzamento de diferentes territórios, em diferentes dimensões, escalas e relações de poder.

4 Este estudo foi realizado como requisito avaliativo da disciplina de Análise de dados quantitativos e qualitativos do curso de Pós-graduação stricto sensu, na modalidade Doutorado, em Sociedade, Tecnologias e Políticas Públicas do Centro Universitário Tiradentes - UNIT/AL. 
A multiterritorialidade contemporânea inclui assim uma mudança não apenas quantitativa - pela maior diversidade de territórios que se colocam ao nosso dispor (ou, pelo menos, das classes e grupos mais privilegiados) - mas também qualitativa, na medida em que temos hoje a possibilidade de combinar de uma forma inédita a intervenção e, de certa forma, a vivência, concomitante, de uma enorme gama de diferentes territórios elou territorialidades (HAESBAERT, 2007, p. 37).

A partir de tais conceitos é possível perceber que a dimensão de território e territorialidade perpassa a individualidade do sujeito, bem como suas coletividades, cultura, relações sociais e políticas, transpondo esse espaço para uma ordem multi, que se constrói e reconstrói constantemente.

A reflexão a seguir se debruça na análise de territorialidade a partir da perspectiva de gênero e da condição de vulnerabilidade da mulher que se encontra no cárcere.

\subsection{TERRITORIALIDADE E MULHERES NO CÁRCERE}

Acredita-se, com base nas leituras e estudos apreciados para a construção do presente ensaio, que as mulheres que se encontram no cárcere estariam acumulando territórios desfavoráveis - "territorialidades ausentes" conforme refere Schefler (2018), em seus contextos de vida.

Ao passo que se entende que as experiências históricos-sociais determinadas pelas diferenças sexuais se sobrepõem ao determinismo econômico, por exemplo, compreende-se que a territorialidade feminina, no cotidiano da relação entre homens e mulheres, é determinada por conflitos interpessoais e coletivos, os quais, em nossa sociedade, reforçam a vulnerabilidade feminina e ratificam o perfil das mulheres no sistema prisional.

Segundo dados do último Levantamento Nacional de Informações Penitenciárias - Infopen Mulheres (2018), bem como dados do Centro de Estudos Estratégicos da Fundação Osvaldo Cruz (2019) e outros estudos, a grande maioria das mulheres que encontra-se em situação de prisão no Brasil é jovem, com idades entre 18 e 35 anos, negra ou parda, possui baixo nível de escolaridade, é fruto de uma família desestruturada, é mãe solteira de em média dois a três filhos, já foi vítima de algum tipo de violência (física, sexual, psicológica) e está presa por delitos relacionados ao tráfico de drogas (BRASIL, 2018; ISAAC; CAMPOS, 2019).

[...] provedoras do sustento familiar, com grande dificuldade de encontrar empregos dignos encontram no crime um meio de prover a sua família o mínimo possível para sobrevivência. Segundo pesquisas $95 \%$ dessas mulheres encarceradas foram vítimas de violência, no mínimo uma vez no decorrer de suas vidas, na maioria das vezes, ainda quando crianças, em seu próprio meio familiar ou então quando adultas submetidas a parceiros ou companheiros em sua vida íntima. Em estudo de toda população carcerária feminina, constatou-se que $68 \%$ delas estão privadas de sua liberdade pelo crime tráfico de drogas. (CAVALLI; XAVIER; WEBER, 2018, p. 24).

Neste sentido, Scott (1989) afirma que a questão do gênero não reflete apenas a realidade biológica, mas constrói o sentido dessa realidade. Corroborando com esta afirmativa, Schefler (2018, p. 
33) aponta que "gênero é uma categoria de análise que permite o entendimento de como a sociedade organiza seus modos de ser, comportamentos e define pertencimentos, revela diferenças, indica desigualdades, enfim, expressa as relações de poder".

A prisão se constitui como um espaço de múltiplas segregações. Para considerar a questão de gênero no sistema penal, há que se ir além de demandas superficiais e/ou estéticas. As mulheres diferem dos homens neste contexto no que diz respeito a vida pregressa ao cárcere, as motivações para o crime, os tipos de crime cometidos, as necessidades quando sob custódia do Estado e no pós-cárcere e o retorno ao convívio familiar, ou seja, numa multiterritorialidade (BARCINSKI; CÚNICO, 2014).

O território prisional é tenso e pesado para todos os seus sujeitos, suas grades e muros não prendem apenas as mulheres no cárcere. A instituição prisional é um território fechado em si e atravessado pelos limites físicos (celas, grades, muros) e subjetivos (pré-conceitos, estigmas, medos, dramas) (DALMASO, 2017).

As pessoas encontram-se privadas de liberdade e lá são postas para permanecerem distantes da sociedade que está do lado de fora - territórios pré-cárcere. No caso das mulheres nesse contexto os territórios de gênero, relações familiares, filhos, relações afetivas e sociais, ou seja, constituem-se multiterritórios e o movimento de des-re-terriorialização se apresenta de forma constante, principalmente com a prospecção de um território pós-cárcere - outro território incerto (PIMENTEL, 2015; QUEIROZ, 2015).

Enquanto espacialidade física, os presídios são estruturas rígidas e não pensadas para relações e territorialidades femininas (QUEIROZ, 2015). Porém, essa espacialidade pode ser considerada uma territorialidade ausente para as mulheres. As relações de grupos (equipes de segurança, mulheres privadas de liberdade) e sujeitos (prisioneiras, agentes penitenciários, entre outros) favorecem e desfavorecem territorialidades, necessitando vivências e relações de sobrevivência para a temporalidade do cárcere.

\section{CONSIDERAÇÕES FINAIS}

Com este estudo foi possível refletir e estabelecer ligações entre territorialidade e as mulheres no cárcere. Ao tomar os conceitos de território e territorialidade um campo de análise se descortina quando nele se projetam as constrições em que se encontram as mulheres privadas de liberdade. Foi observado que existem multiterritórios e multiterritorialidades no aprisionamento feminino, com clivagens de gênero, poder e vulnerabilidades. Ademais, há uma reafirmação de territorialidades ausentes vivenciadas nos espaços dessas mulheres.

\section{REFERÊNCIAS}

BARCINSKI, Mariana; CÚNICO, Sabrina Daiana. Os efeitos (in)visibilizadores do cárcere: as contradições do sistema prisional. Revista Psicologia, v. 28, n. 2, p. 63-70, 2014. Disponível em: http://www.scielo. mec.pt/scielo.php?script=sci_arttext๕pid=S0874-20492014000200006. Acesso em: 15 nov. 2019. 
BRASIL. Portaria interministerial n 210, de 16 de janeiro de 2014. Institui a Política Nacional de Atenção às Mulheres em Situação de Privação de liberdade e Egressas do Sistema Prisional, e dá outras providências. República Federativa do Brasil. Imprensa Nacional Brasília - DF, nº 12, DoU, 17/01/14, seção 1, p. 75. Disponível em: http://bvsms.saude.gov.br/bvs/saudelegis/gm/2014/ pri0001_02_01_2014.html. Acesso em: 14 nov. 2018.

BRASIL. Ministério da Justiça. Levantamento Nacional de Informações Penitenciárias - InfoPen Mulheres - 2. ed. Organização Thanara Santos, colaboração Marlene Inês da Rocha et al. Brasília: Ministério da Justiça e Segurança Pública. Departamento Penitenciário Nacional, 2018. Disponível em: http://depen.gov.br/DEPEN/depen/sisdepen/infopen-mulheres/infopenmulheres_arte_07-0318.pdf. Acesso em: 19 dez. 2019.

BRASIL. Ministério da Saúde. FUNASA. Portaria n. 586, 14 de julho de 2014. Disponível em: http:// bvsms.saude.gov.br/bvs/saudelegis/funasa/2014/prt0586_14_07_2014.html. Acesso em: 17 nov. 2019.

CAVALLI, Luana; XAVIER, Suelen Camargo; WEBER, Suelen da Silva. Situação carcerária feminina. Congresso de Direitos Humanos da Faculdade da Serra Gaúcha (FSG), 2, de 20 e 21 de junho de 2018. Anais [...], Caxias do Sul, RS. Disponível em: http://fsg.br/congressodedireitoshumanos. Acesso em: 22 out. 2019.

\section{DALMASO, Tatiana Fraga. Produção de territórios na interface da saúde com a segurança} pública: cuidado em saúde para mulheres privadas de liberdade. 2017. Dissertação (Mestrado) Universidade Federal do Rio Grande do Sul, Porto Alegre, RS, 2017.

DELEUZE, Guiles; GUATTARI, Félix. Acerca do ritornelo. Tradução de Suely Rolnik. In: DELEUZE, Gilles; GUATTARI, Felix. Mil platôs - capitalismo e esquizofrenia. V. 4. São Paulo: Ed. 54, 1997 (Coleção TRANS).

HAESBAERT, Rogério. Território e multiterritorialidade: um debate. GEOgraphia - Ano IX, n. 17, 2007. Disponível em: http://periodicos.uff.br/geographia/article/view/13531. Acesso em: 15 nov. 2019.

HAESBAERT, Rogério; BRUCE, Glauco. A desterritorialização na obra de Deleuze e Guattari. GEOgraphia, v. 4, n. 7, 2002. Disponível em: http://periodicos.uff.br/geographia/article/ view/13419/8619. Acesso em: 16 nov. 2019.

ISAAC, Fernanda Fulani; CAMPOS, Tales de Paula Roberto de. 0 encarceramento feminino no

Brasil. Centro de Estudos Estratégicos da Fundação Osvaldo Cruz, 2019. Disponível em: https://cee. fiocruz.br/?q=node/997. Acesso em: 19 dez. 2019. 
PIMENTEL, Elaine. As mulheres e a vivência pós-cárcere. Maceió: EDUFAL, 2015.

QUEIROZ, Nana. Presos que menstruam. Rio de Janeiro, RJ: Record, 2015.

SCHEFLER, Maria de Lourdes Noaves. Território e gênero territorialidades ausentes. In: RODRIGUES, Cristiano et al. (org.). Territorialidades dimensões de gênero, desenvolvimento e empoderamento das mulheres. Salvador: EDUFBA, 2018.

SCOTT, Joan Wallach. Gênero: uma categoria útil de análise histórica. Educação \& Realidade, Porto Alegre, v. 20, n. 2, p. 71-99, jul./dez. 1995. 
1 Mestre em Enfermagem pelo Programa de Pós-graduação em Enfermagem - ESENFAR-UFAL; Doutoranda em Sociedade, Tecnologias e Políticas Públicas - UNIT/AL; Especialista em Enfermagem Obstétrica pela Universidade de Ciências da Saúde de Alagoas - UNCISAL; Graduada pela Universidade Federal de Alagoas - UFAL (2006); Enfermeira. E-mail: albambf@hotmail.com

2 Doutora em Antropologia pela Universidade Federal de Pernambuco (2007); Pós-Doutorado pelo Programa de Pós-Graduação em Estudos Interdisciplinares sobre Mulheres, Gênero e Feminismo (PPGNEIM) da Universidade Federal da Bahia (2018); Professora Titular I do Programa de Pós-Graduação em Sociedade, Tecnologias e Políticas Públicas (Mestrado e Doutorado) - SOTEPP do Centro Universitário Tiradentes - UNIT/AL. E-mail: jesanabpereira@gmail.com

3 Doutora em Ciências Jurídicas pela Universidade Federal da Paraíba (UFPB); Professora de Direito Internacional e Direitos Humanos no Centro Universitário Tiradentes e Titular I do Programa de Pós-Graduação em Sociedade, Tecnologias e Políticas Públicas (Mestrado e Doutorado) SOTEPP do Centro Universitário Tiradentes.

E-mail: viviannygalvao@hotmail.com

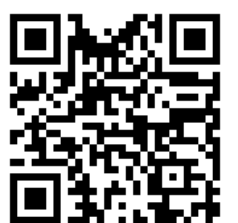

A autenticidade desse artigo pode ser conferida no site https://periodicos. set.edu.br

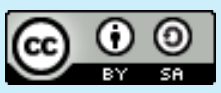

Este artigo é licenciado na modalidade acesso abertosob a Atribuição-Compartilhalgual CC BY-SA

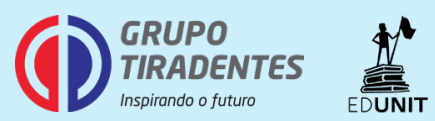

